\title{
Quality of life improves after thoracoscopic surgical ablation of advanced atrial fibrillation: Results of the Atrial Fibrillation Ablation and Autonomic Modulation via Thoracoscopic Surgery (AFACT) study
}

Antoine H. G. Driessen, MD, ${ }^{\mathrm{a}}$ Wouter R. Berger, MD, ${ }^{\mathrm{b}}$ Mark F. A. Bierhuizen, BSc, ${ }^{\mathrm{b}}$

Femke R. Piersma, RN, ${ }^{\mathrm{b}}$ Nicoline W. E. van den Berg, MD, ${ }^{\mathrm{b}}$ Jolien Neefs, MD, ${ }^{\mathrm{b}}$ Sébastien P. J. Krul, MD, PhD, ${ }^{\mathrm{b}}$ WimJan P. van Boven, MD, PhD, ${ }^{a}$ and Joris R. de Groot, MD, $\mathrm{PhD}^{\mathrm{b}}$

\section{ABSTRACT}

Objective: We evaluated health-related quality of life at 12 months after thoracoscopic surgical ablation in patients enrolled in the Atrial Fibrillation Ablation and Autonomic Modulation via Thoracoscopic Surgery study. The Atrial Fibrillation Ablation and Autonomic Modulation via Thoracoscopic Surgery study assessed the efficacy and safety of ganglion plexus ablation in patients with symptomatic advanced atrial fibrillation undergoing thoracoscopic surgical ablation.

Methods: Patients $(\mathrm{n}=240)$ underwent thoracoscopic pulmonary vein isolation with additional ablation lines in patients with persistent atrial fibrillation. Subjects were randomized to additional ganglion plexus ablation or control. Short Form 36 quality of life questionnaires were collected at baseline and at 6 and 12 months of follow-up.

Results: A total of 201 patients were eligible for quality of life analysis (age $59 \pm 8$ years, $72 \%$ were men, $68 \%$ had an enlarged left atrium, $57 \%$ had persistent atrial fibrillation). Patients improved in physical and mental health at 6 months (both $P<.01$ ) and 12 months (both $P<.01$ ) relative to baseline, with no difference between the ganglion plexus $(\mathrm{n}=101)$ and control $(\mathrm{n}=100)$ groups. Short Form 36 subscores in patients with 1 or no atrial fibrillation recurrences were similar to those in the general Dutch population after 12 months. Patients with multiple atrial fibrillation recurrences (30\%) improved in mental $(P<.01)$, but not physical health, and 6 of 8 Short Form 36 subscales remained below those of the general Dutch population. Patients with irreversible, but not with reversible procedural complications had persistently diminished quality of life scores at 12 months.

Conclusions: Thoracoscopic surgery for advanced atrial fibrillation results in improvement in quality of life, regardless of additional ganglion plexus ablation. Quality of life in patients with no or 1 atrial fibrillation recurrence increased to the level of the general Dutch population, whereas in patients with multiple atrial fibrillation recurrences quality of life remained lower. Irreversible but not reversible procedural complications were associated with persistently lower quality of life. (J Thorac Cardiovasc Surg 2018;155:972-80)

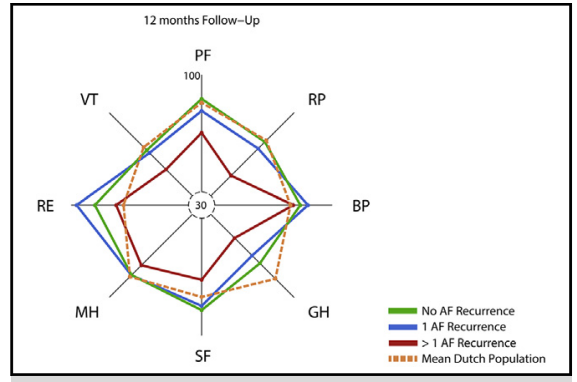

Improvement of QoL in relation to recurrences of $\mathrm{AF}$. A radar chart with the SF-36 scores of patients with more than $1 \mathrm{AF}$ recurrence (red), $1 \mathrm{AF}$ recurrence (blue), and no AF recurrences (green) is shown at 12 months follow-up after thoracoscopic AF surgery. Dutch population means are denoted by the dashed orange lines.

\section{Central Message}

QoL improvement after thoracoscopic surgery for $\mathrm{AF}$ relates to $\mathrm{AF}$ recurrences and procedural complications.

\section{Perspective}

By using the SF-36 questionnaire, we show that QoL improves after thoracoscopic surgery for AF. Patients with irreversible surgical complications or multiple AF recurrences demonstrated no improvement of QoL. A single AF recurrence was associated with the same $\mathrm{QoL}$ improvement as were no $\mathrm{AF}$ recurrences at all.

See Editorial Commentary page 981.

See Editorial page 970.
From the Departments of ${ }^{\mathrm{a} C}$ ardiothoracic Surgery and ${ }^{\mathrm{b}}$ Cardiology, Heart Center, Academic Medical Center, University of Amsterdam, Amsterdam, The Netherlands. The AFACT study was supported in part by personal grants to J.R.dG. from the Dutch Heart Foundation (2009T021) and NWO/ZonMW (106.146.310) and by an unrestricted grant from Atricure Inc.

A.H.G.D. and W.R.B. contributed equally to this article

Registered at clinicaltrials.gov: NCT01091389.
Received for publication May 19, 2017; revisions received Aug 21, 2017; accepted for publication Sept 18, 2017; available ahead of print Nov 1, 2017.

Address for reprints: Joris R. de Groot, MD, PhD, Heart Center, Department of Cardiology, Academic Medical Center, Meibergdreef 9, Amsterdam 1100 DD, The Netherlands (E-mail: j.r.degroot@amc.uva.nl). $0022-5223 / \$ 36.00$

Copyright (c) 2017 by The American Association for Thoracic Surgery https://doi.org/10.1016/j.jtcvs.2017.09.093 


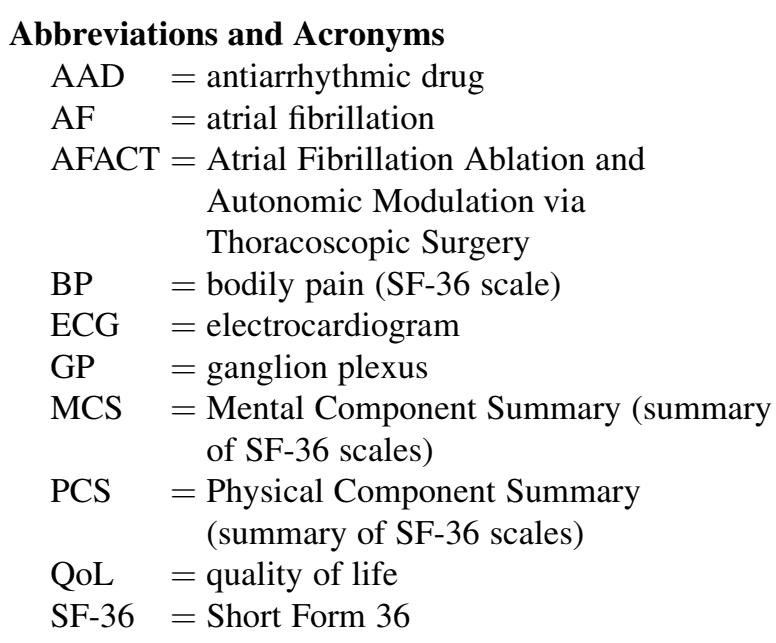

Scanning this $Q R$ code will take you to a supplemental video for the article.

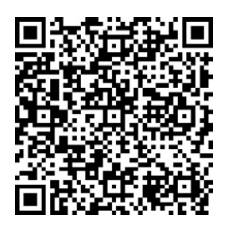

Atrial fibrillation (AF) is the most common cardiac arrhythmia, estimated to affect 33.5 million people worldwide. Its prevalence is increasing as a result of the aging population and the improved survival of chronic cardiovascular disease. ${ }^{1,2}$ Health-related quality of life $(\mathrm{QoL})$ in patients with $\mathrm{AF}$ is generally lower than the population norms. ${ }^{3}$

Rhythm control with catheter or surgical ablation is recommended for patients remaining symptomatic despite a trial with antiarrhythmic drugs (AADs), and invasive AF treatment may improve QoL. ${ }^{4}$ After catheter ablation, QoL has been reported to improve regardless of procedural success. It has been demonstrated that a substantial reduction in $\mathrm{AF}$ burden results in a significant improvement of QoL, whereas QoL changes less in patients with more AF recurrences. ${ }^{5-7}$ Similar to catheter ablation, thoracoscopic surgery for AF is performed to achieve freedom of AF and may further even reduce risk factors for stroke and heart failure. ${ }^{8}$ However, improvement of the patient's symptoms remains central in the indication for invasive AF management. ${ }^{4}$ Thoracoscopic surgery for AF has been associated with high efficacy rates. It has been suggested that its higher efficacy goes at the cost of more procedural complications compared with catheter ablation, and therefore potentially negatively affects QoL. ${ }^{9}$ However, prospective data on QoL in patients undergoing thoracoscopic surgery for AF are lacking.

The Atrial Fibrillation Ablation and Autonomic Modulation via Thoracoscopic Surgery (AFACT) study demonstrated no efficacy of additional ganglion plexus (GP) ablation in patients with advanced $\mathrm{AF}$ undergoing thoracoscopic AF surgery, but there was an increased incidence of complications compared with the control group. ${ }^{10}$ The aim of this prespecified substudy of AFACT was to determine the change in QoL after thoracoscopic AF ablation in relation to additional GP ablation, freedom of $\mathrm{AF}$ recurrence, and procedural complications.

\section{MATERIALS AND METHODS \\ Study Design}

The AFACT study compared the efficacy and safety of additional GP ablation with no additional GP ablation in patients with advanced paroxysmal or persistent AF undergoing thoracoscopic surgery for AF. The study was registered at clinicaltrials.gov (NCT01091389) and approved by the institutional review board of the Academic Medical Center. All patients provided written informed consent. The methods and main clinical findings have been published. ${ }^{10,11}$ In brief, the study included patients with advanced $\mathrm{AF}$, that is, mostly persistent $\mathrm{AF}$, with enlarged left atria or previously failed catheter ablation, refractory or intolerant to at least $1 \mathrm{AAD}$, undergoing thoracoscopic surgical ablation. All patients $(n=240)$ were subjected to thoracoscopic pulmonary vein isolation $(\geq 6 \mathrm{RF}$ applications to the pulmonary vein antrum with the AtriCure Isolator Synergy bipolar RF ablation clamp; AtriCure Inc, Mason, Ohio). Video 1 provides a summary of the surgical procedure. In patients with persistent $\mathrm{AF}$, additional left atrial lines were ablated conforming to the Dallas lesion set. ${ }^{12}$ Patients were randomized to additional ablation of the 4 major ganglionic plexi and Marshall's ligament $(\mathrm{n}=117)$ or no additional GP ablation (control group, $\mathrm{n}=123$ ).

\section{Clinical Follow-up}

Patients were followed up every 3 months with electrocardiogram (ECG) and 24-hour Holter monitoring performed at every follow-up visit for 1 year. Patients were encouraged to obtain additional rhythm recording when symptomatic. AF recurrences were defined as any episode of AF, atrial tachycardia, or atrial flutter documented on ECG or 24-hour Holter lasting more than 30 seconds. A blanking period of 3 months after the procedure was instituted during which $\mathrm{AF}$ recurrences were not considered a clinical end point. ${ }^{8}$ All AADs were discontinued 3 months after the procedure, unless the patient continued to have AF. Procedural complications were defined as major when causing (prolongation of) hospital admission within 30 days. ${ }^{10}$ Of those, events were defined as irreversible when injury was permanent (ie, pacemaker implantation, stroke, or phrenic paralysis) or when the thoracoscopic procedure could not be completed. ${ }^{10}$

\section{Health-Related Quality of Life Form}

Assessment of change in QoL was a prespecified analysis of the AFACT study, and Short Form 36 (SF-36) QoL questionnaires were filled out before randomization and at 6 and 12 months follow-up. The SF-36 QoL questionnaire is a validated generic questionnaire to measure physical and mental health in individuals. It consists of 36 questions, grouped into 8 scales: physical functioning, role physical, bodily pain (BP), social functioning, mental health, role emotional, vitality, and general health perception. The 8 scales are summarized in 2 dimensions, Physical Component Summary (PCS) and Mental Component Summary (MCS), normalized to an overall population mean \pm standard deviation of $50 \pm 10$. The 8 scales and 2 summary dimensions are transformed to a scale from 0 to 100 , where 100 is the best possible health, as described by Ware and colleagues. ${ }^{13}$ The scores from a dataset displaying the QoL in the general Dutch population were used as a reference. ${ }^{14}$ 


\section{Statistical Analysis}

Statistical analyses were performed using SPSS version 23.0 (SPSS Inc, Chicago, Ill) and $\mathrm{R}$ for Windows version 3.1.1. Continuous data are reported as mean \pm standard deviation, and categoric data are reported as number of subjects and proportions. Because there were no differences in any of the SF-36 subscales, the treatment arms of AFACT were combined for the current analysis. The baseline characteristics were compared using the chi-square test for categoric data and Student unpaired $t$ test for normally distributed data or the Mann-Whitney $U$ test for non-normally distributed data. Normal distribution was tested with the Kolmogorov-Smirnov test. Student unpaired $t$ test was used to compare the mean scores in SF-36 subscales between groups. To compare data from the SF-36 questionnaire with the reference population, a 1-sample $t$ test was used. For comparing QoL on the 8 subscales and 2 summary dimensions after thoracoscopic ablation relative to baseline, the paired sample $t$ test was used.

For univariable and multivariable analyses, simple linear regression and stepwise multivariable regression were used to study predictors for the change in MCS and PCS scores after 12 months. Graphic analyses of the residuals indicated that the assumptions of linear regression were met. All variables with a $P$ value less than .01 in univariable analysis were entered in the multivariable regression.

\section{RESULTS \\ Study Population}

Of the 240 patients included in the AFACT study, 13 were not included in the present analysis; 4 patients died, 2 procedures were aborted, and 7 patients were lost to follow-up. An additional 26 patients did not complete the SF-36 questionnaires at baseline or at 6 or 12 months followup ( 9 in the GP group and 17 in the controls). For the present study, 201 patients with complete SF-36 questionnaires at baseline and 6 and 12 months (101 in the GP group and 100 in the control group) were analyzed. Mean age was $59 \pm 8$ years, $72 \%$ were men, mean left atrial volume index was $39.0 \pm 11.6 \mathrm{~mL} / \mathrm{m}^{2}$, and 114 patients $(57 \%)$ had persistent AF. Baseline characteristics are displayed in Table 1.

\section{Health-Related Quality of Life}

There were no differences in QoL with respect to any of the 8 social functioning subscales or on PCS or MCS between the GP ablation group and no GP ablation group at baseline and 6 months or 12 months (Figure 1 and Table 2). Patients with advanced AF scored significantly lower than the general Dutch population before the ablation procedure in 7 of the 8 scales in SF-36, with the exception of BP. PCS and MCS were $44.6 \pm 9.4$ and $45.0 \pm 10.9$, respectively. Table 3 shows that scores in all 7 subscales were significantly higher after 12 months in the full cohort. This increase was reached after 6 months and persisted up to 12 months. Subsequently, PCS and MCS were significantly higher after 6 and 12 months $(P<.001$ and $P<.001$, respectively).

\section{Adverse Events}

The complications during the course of the study have been published, and major procedural complications occurred more often in patients undergoing GP ablation. ${ }^{10}$ In the present analysis, 31 patients $(15 \%)$ had major procedural
TABLE 1. Baseline characteristics

\begin{tabular}{|c|c|}
\hline Patients, $\mathrm{n}$ & 201 \\
\hline Age $(y)$, mean \pm SD (range) & $59.6 \pm 7.8(39-73)$ \\
\hline Male, $n(\%)$ & $145(72)$ \\
\hline \multicolumn{2}{|l|}{ Type AF } \\
\hline Paroxysmal, n (\%) & $87(43)$ \\
\hline Persistent, $\mathrm{n}(\%)$ & $114(57)$ \\
\hline AF duration $(\mathrm{y})$, median [IQR] & $4[2-8]$ \\
\hline Congestive heart failure, $\mathrm{n}(\%)$ & $7(4)$ \\
\hline Hypertension, $\mathrm{n}(\%)$ & $87(43)$ \\
\hline Age $\geq 75 y, n(\%)$ & $0(0)$ \\
\hline Diabetes, n (\%) & $13(7)$ \\
\hline Stroke/TIA/embolus, n (\%) & $16(8)$ \\
\hline Vascular disease, n (\%) & $18(9)$ \\
\hline Female gender, $\mathrm{n}(\%)$ & $56(28)$ \\
\hline Age $\geq 65 y, n(\%)$ & $56(28)$ \\
\hline \multicolumn{2}{|l|}{$\mathrm{CHA}_{2} \mathrm{DS}_{2}$ VASc score } \\
\hline $0, \mathrm{n}(\%)$ & $56(28)$ \\
\hline $1, \mathrm{n}(\%)$ & $66(33)$ \\
\hline$\geq 2, \mathrm{n}(\%)$ & $79(39)$ \\
\hline Previous catheter PVI, n (\%) & $51(25)$ \\
\hline Previous PCI, n (\%) & $22(11)$ \\
\hline Myocardial infarction, n (\%) & $9(5)$ \\
\hline BMI $\left(\mathrm{kg} / \mathrm{m}^{2}\right)$, mean $\pm \mathrm{SD}$ & $27.1 \pm 3.8$ \\
\hline \multicolumn{2}{|l|}{ Echocardiographic parameters } \\
\hline Left atrial volume $(\mathrm{mL})$, mean $\pm \mathrm{SD}$ & $81.1 \pm 23.2$ \\
\hline Left atrial volume index $\left(\mathrm{mL} / \mathrm{m}^{2}\right)$, mean $\pm \mathrm{SD}$ & $39.0 \pm 10.6$ \\
\hline Left atrial diameter $(\mathrm{mm})$, mean $\pm \mathrm{SD}$ & $42.2 \pm 5.4$ \\
\hline $\operatorname{LVEF}(\%)$, mean $\pm \mathrm{SD}$ & $50.6 \pm 9.7$ \\
\hline \multicolumn{2}{|l|}{ Antiarrhythmic drugs } \\
\hline Class IA, n (\%) & $4(2)$ \\
\hline Class IC, $\mathrm{n}(\%)$ & $69(35)$ \\
\hline Class II, n (\%) & $122(49)$ \\
\hline Class III, n (\%) & $79(39)$ \\
\hline Class IV, n (\%) & $27(13)$ \\
\hline Digoxin, n (\%) & $23(11)$ \\
\hline \multicolumn{2}{|l|}{ Anticoagulants } \\
\hline Acenocoumarol, n (\%) & $153(76)$ \\
\hline Phenprocoumon, n (\%) & $21(10)$ \\
\hline NOAC, n $(\%)$ & $26(14)$ \\
\hline Antiplatelets, n (\%) & $13(7)$ \\
\hline
\end{tabular}

$\overline{S D \text {, Standard deviation; } A F \text {, atrial fibrillation; } I Q R \text {, interquartile range; } T I A \text {, transient }}$ ischemic attack; $\mathrm{CHA}_{2} \mathrm{DS}_{2} \mathrm{VASc}$, congestive heart failure [C], hypertension $[\mathrm{H}]$, age $>75$ years ( 2 points) $\left[\mathrm{A}_{2}\right]$, diabetes [D], previous stroke ( 2 points) $\left[\mathrm{S}_{2}\right]$, vascular disease [V], age 65-74 years [A], female sex [Sc]; $P V I$, pulmonary vein isolation; $P C I$, percutaneous coronary intervention; $B M I$, body mass index; $L V E F$, left ventricular ejection fraction; NOAC, new oral anticoagulant.

complications and 16 patients ( $8 \%$ ) had minor complications. Ten major complications $(5 \%)$ were irreversible.

Table 4 shows that there was no difference in any of the SF-36 subscales or on PCS and MCS at baseline in patients compared with patients without any major procedural 

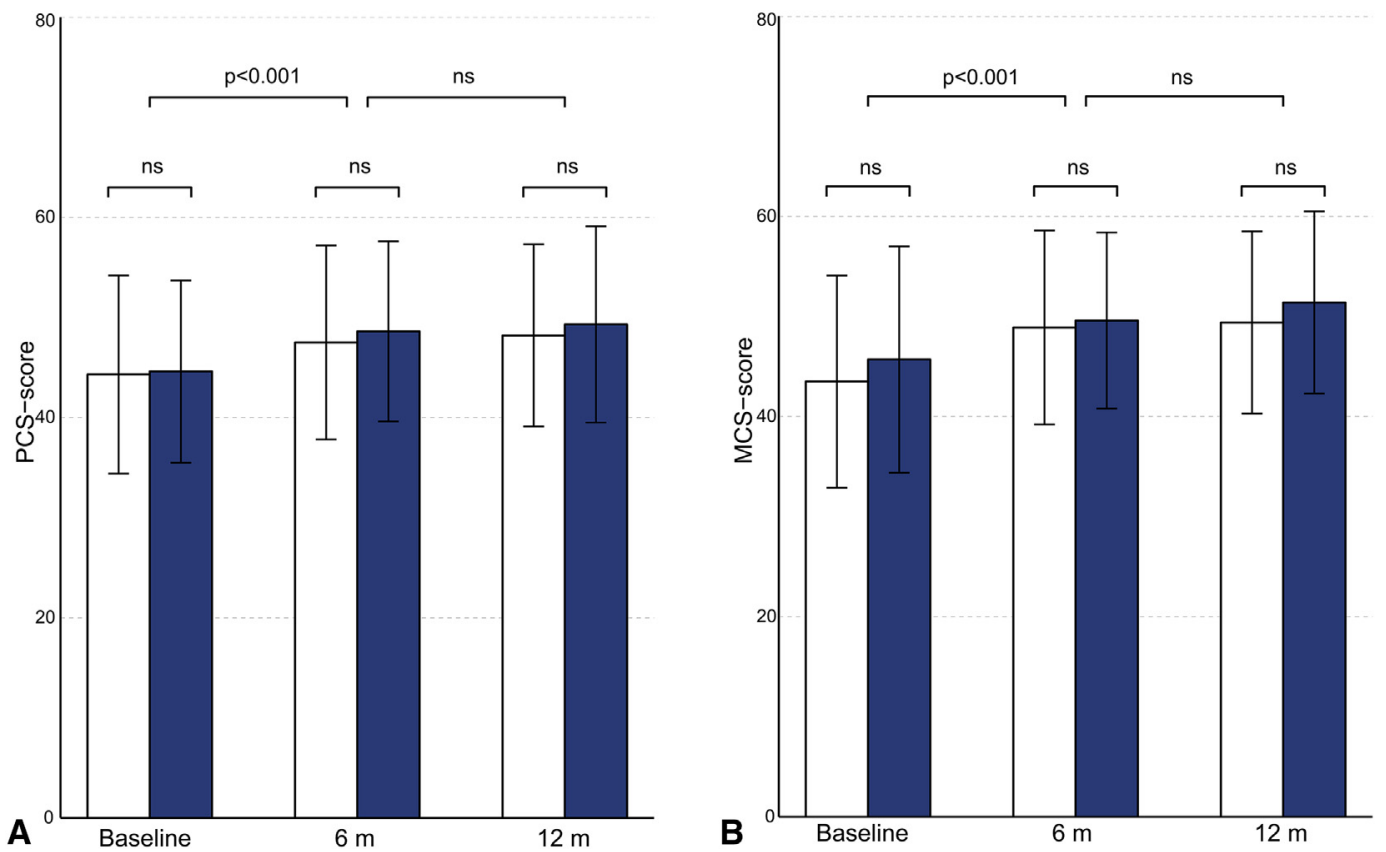

FIGURE 1. PCS (A) and MCS (B) scores at baseline and 6 and 12 months after thoracoscopic ablation are shown for the GP ablation (blue) and control (white) arms of the study. PCS, Physical Component Summary; MCS, Mental Component Summary.

complications. Figure 2, A, shows that patients with irreversible procedural complications (most often consisting of pacemaker implantation) did not demonstrate improvement on MCS and subscales compared with the patients without complications. Patients with reversible periprocedural events or bleeding eventually improved to the same extent as patients without events (Figure 2, B). Consequently, there were no significant differences on the combined scores or any of the subscores between patients with and without reversible complications at 12 months.

\section{Absence of Atrial Fibrillation}

Of the total study population, 141 patients $(70 \%)$ discontinued $\mathrm{AAD}$ and did not experience $\mathrm{AF}$ recurrence during 1 year of follow-up. Irrespective of AF absence, $83 \%$ of patients $(\mathrm{n}=167)$ were not using AAD at 12 months follow-up.

At baseline, no significant differences were observed in any of the SF-36 subscales and PCS and MCS between patients who would experience $\mathrm{AF}$ recurrence versus those without $\mathrm{AF}$ recurrence. As expected, and consistent with the finding in the entire cohort, $\mathrm{BP}$ was similar in $\mathrm{AF}$ patients at baseline as in the general Dutch population. Table 3 summarizes the change in SF-36 subscales during follow-up in patients with and without AF recurrences.

Thirty-three patients (16\%) had an AF recurrence before they completed the 6-month follow-up SF-36 questionnaire. These patients did not show improvement on any of the

TABLE 2. Baseline Short Form 36 quality of life stratified to randomization in AFACT

\begin{tabular}{lccc}
\hline & All & No GP & GP ablation \\
\hline No. of patients & 201 & 100 & 101 \\
SF-36 summary & & & \\
$\quad$ PCS, mean \pm SD & $44.4 \pm 9.5$ & $44.3 \pm 9.9$ & $44.6 \pm 9.1$ \\
MCS, mean \pm SD & $44.6 \pm 11.0$ & $43.5 \pm 10.6$ & $45.7 \pm 11.3$ \\
SF-36 domains & & & .81 \\
Physical functioning, mean \pm SD & $66.5 \pm 25.6$ & $67.3 \pm 25.8$ & $65.7 \pm 25.5$ \\
Role physical, mean \pm SD & $37.2 \pm 42.7$ & $36.4 \pm 42.15$ & $38.0 \pm 43.4$ \\
BP, mean \pm SD & $81.7 \pm 21.9$ & $79.5 \pm 22.5$ & $83.7 \pm 21.1$ \\
Social functioning, mean \pm SD & $67.4 \pm 24.7$ & $64.8 \pm 23.5$ & $70.0 \pm 25.7$ \\
Mental health, mean \pm SD & $72.0 \pm 17.6$ & $70.9 \pm 16.8$ & $73.5 \pm 18.3$ \\
Role emotional, mean \pm SD & $71.9 \pm 41.6$ & $68.7 \pm 43.0$ & .66 \\
Vitality, mean \pm SD & $49.1 \pm 21.2$ & $48.2 \pm 21.9$ & .79 \\
General health perception, mean \pm SD & $60.9 \pm 19.2$ & $59.7 \pm 19.7$ & .17 \\
\hline
\end{tabular}

GP, Ganglion plexus; SF-36, Short Form-36; PCS, Physical Component Summary; SD, standard deviation; $M C S$, Mental Component Summary; $B P$, bodily pain. 
TABLE 3. Mean changes between baseline and 12 months of follow-up

\begin{tabular}{lcc}
\hline & 12-mo change vs baseline & $\boldsymbol{P}$ value \\
\hline Entire cohort, $\mathrm{n}$ & 201 & \\
PCS & $4.0(2.7-5.4)$ & $<.001$ \\
Physical functioning & $13.7(10.4-17.0)$ & $<.001$ \\
Role physical & $31.5(24.2-38.8)$ & $<.001$ \\
BP & $-1.4(-4.6$ to 1.9$)$ & .41 \\
General health perceptions & $5.2(2.6-7.8)$ & $<.001$ \\
MCS & $5.3(3.8-6.8)$ & $<.001$ \\
Social functioning & $13.3(10.1-16.6)$ & $<.001$ \\
Mental health & $7.1(5.0-9.1)$ & $<.001$ \\
Role emotional & $11.3(5.1-17.5)$ & $<.001$ \\
Vitality & $15.6(12.9-18.4)$ & $<.001$ \\
No AF recurrence group, $\mathrm{n}$ & 141 & \\
PCS & $5.8(4.3-7.4)$ & $<.001$ \\
Physical functioning & $16.9(13.1-20.8)$ & $<.001$ \\
Role physical & $38.0(29.4-46.7)$ & $<.001$ \\
BP & $-0.1(-3.7$ to 3.6$)$ & .976 \\
General health perceptions & $8.8(5.7-11.8)$ & $<.001$ \\
MCS & $5.3(3.5-7.0)$ & $<.001$ \\
Social functioning & $15.9(12.0-19.7)$ & $<.001$ \\
Mental health & $8.1(5.6-10.5)$ & $<.001$ \\
Role emotional & $9.7(2.2-17.3)$ & .012 \\
Vitality & $17.8(14.5-21.0)$ & $<.001$ \\
AF recurrence group, $\mathrm{n}$ & 60 & \\
PCS & $-0.4(-2.7$ to 1.9$)$ & .719 \\
Physical functioning & $6.1(0.0-12.2)$ & .051 \\
Role physical & $15.9(2.5-29.4)$ & .021 \\
BP & $-4.5(-11.2$ to 2.2$)$ & .189 \\
General health perceptions & $-3.2(-7.9$ to 1.5$)$ & .182 \\
MCS & $5.3(2.4-8.2)$ & .001 \\
Social functioning & $7.3(1.4-13.2)$ & .016 \\
Mental health & $4.9(-0.9$ to 8.8$)$ & .017 \\
Role emotional & $14.9(4.3-25.9)$ & .008 \\
Vitality & $10.7(5.7-15.6)$ & $<.001$ \\
\hline (95\% cont & & \\
\hline
\end{tabular}

Mean (95\% confidence interval). PCS, Physical Component Summary; $B P$, bodily pain; $M C S$, Mental Component Summary; $A F$, atrial fibrillation.

8 subscales, whereas patients without recurrence at 6 months showed significant improvement on 7 of 8 subscales, except on BP and in PCS and MCS (PCS: $P<.001$, MCS: $P<.001)$ at 6 months. After 12 months, patients with AF recurrences had lower scores on 6 of 8 subscales than those without $\mathrm{AF}$ recurrences with exception of BP and role emotional. Likewise, PCS and MCS were significantly lower in patients with $\mathrm{AF}$ recurrences compared with patients without $\mathrm{AF}$ recurrence $(P=.001$ and $P=.023$, respectively).

In the AF recurrence group, PCS did not significantly change compared with baseline $(P=.567)$, but MCS did increase after 12 months $(P=.001)$. QoL scores remained decreased in physical functioning, role physical, social functioning, vitality, and general health in these patients (Figure 3). Twenty-seven patients (13\%) had no recurrence at 6 months but at least 1 recurrence at 12 months follow-up. In those patients, PCS was significantly lower than in patients without $\mathrm{AF}$ at both $6(P=.021)$ and 12 months $(P=.001)$. MCS was equal compared with the nonrecurrence group at 6 months $(P=.332)$, but was significantly decreased at 12 months follow-up $(P=.032)$.

\section{Role of the Number of Documented Atrial Fibrillation Recurrences}

To evaluate the effect of the AF burden, we compared the change in SF-36 scores in patients with 1 AF recurrence $(\mathrm{n}=19)$ versus those with multiple AF recurrences $(n=41)$. There were no significant differences in any of the subscales or in PCS and MCS at baseline. Furthermore, baseline QoL subscale scores were not different from those of patients without AF recurrences. Figure 4 summarizes that patients with only $1 \mathrm{AF}$ recurrence improved on the SF-36 subscales, similar to the group with no AF recurrence, whereas in patients with multiple AF recurrences the SF-36 subscales did not change after the procedure and remained significantly lower than those of the general Dutch population.

\section{Predictors of Change in Quality of Life}

Table 5 displays the univariable and multivariable predictors of change in MCS and PCS scores after 12 months relative to baseline. In multivariable analysis, AF recurrence within 12 months $(P=.001)$ and PCS at baseline $(P<.001)$ remained independent predictors of decreased PCS. For MCS, only the experience of major procedural complications $(P=.049)$ and MCS score at baseline $(P<.001)$ were predictors of decrease at 12 months in univariable analysis. In multivariable analysis, these factors remained independent predictors of decreased MCS.

\section{DISCUSSION}

In this predefined subanalysis of the AFACT study, we demonstrate that QoL significantly increases after thoracoscopic surgery in all patients with advanced AF, both with and without GP ablation. We show that QoL improves in the entire cohort after thoracoscopic surgery. The most important determinant of absence of QoL improvement was AF recurrence. Patients with AF recurrence had a lower QoL than those without. Also, patients with a recurrence after more than 6 months showed a decreased QoL at 12 months compared with 6 months. One single AF recurrence appears to only temporarily decrease QoL, because in those patients there was no difference in the SF-36 subscales or in the domains compared with patients without AF after 12 months. Multiple AF recurrences were associated with a significantly decreased QoL. Baseline QoL, AF recurrence, and procedural complications independently predicted a lower QoL. This observation suggests that AF recurrence and the burden of recurrences, rather than the characteristics or invasiveness of the surgical procedure, drive the change in QoL. In 
TABLE 4. Physical Component Summary and Mental Component Summary at baseline and during follow-up

\begin{tabular}{|c|c|c|c|c|c|c|c|c|c|}
\hline & $\begin{array}{c}\text { No GP } \\
\mathbf{n}=101\end{array}$ & $\begin{array}{c}\text { GP } \\
n=100\end{array}$ & $P$ value & $\frac{\text { No AF recurrence }}{n=141}$ & $\frac{\text { AF recurrence }}{n=60}$ & $P$ value & $\frac{\text { No major AE }}{n=170}$ & $\frac{\text { Major AE }}{n=31}$ & $P$ value \\
\hline \multicolumn{10}{|l|}{ Baseline } \\
\hline PCS & $44.3 \pm 9.9$ & $44.6 \pm 9.1$ & .814 & $44.8 \pm 9.7$ & $43.6 \pm 8.8$ & .415 & $44.8 \pm 9.4$ & $42.6 \pm 9.7$ & .234 \\
\hline MCS & $43.5 \pm 10.6$ & $45.7 \pm 11.3$ & .151 & $45.4 \pm 10.2$ & $42.7 \pm 12.6$ & .112 & $44.4 \pm 11.0$ & $45.8 \pm 10.9$ & .534 \\
\hline \multicolumn{10}{|l|}{$6 \mathrm{mo}$} \\
\hline PCS & $47.5 \pm 9.7$ & $49.6 \pm 9.0$ & .128 & $50.3 \pm 8.9$ & $44.6 \pm 9.5$ & $<.001$ & $49.1 \pm 9.0$ & $45.3 \pm 11.1$ & .039 \\
\hline MCS & $48.6 \pm 9.7$ & $50.7 \pm 8.8$ & .106 & $50.5 \pm 8.8$ & $47.7 \pm 10.1$ & .05 & $49.7 \pm 9.0$ & $49.3 \pm 10.8$ & .831 \\
\hline \multicolumn{10}{|l|}{$12 \mathrm{mo}$} \\
\hline PCS & $48.2 \pm 9.1$ & $49.3 \pm 9.8$ & .436 & $51.0 \pm 8.3$ & $43.6 \pm 10.0$ & $<.001$ & $49.3 \pm 8.9$ & $45.8 \pm 11.7$ & .062 \\
\hline MCS & $49.4 \pm 9.1$ & $51.1 \pm 9.1$ & .181 & $51.2 \pm 8.4$ & $48.0 \pm 10.3$ & .023 & $50.8 \pm 8.7$ & $47.6 \pm 10.7$ & .083 \\
\hline
\end{tabular}

Data are presented as mean \pm standard deviation. Bold indicates significant changes $(P<.05)$. GP, Ganglion plexus; $A F$, atrial fibrillation; $A E$, adverse event; $P C S$, Physical Component Summary; MCS, Mental Component Summary.

addition, a baseline low QoL is associated with limited improvement after surgery. These data support the use of $\mathrm{AF}$ symptoms, as advocated in the guidelines, as an indication for invasive therapy. ${ }^{8,15}$

Patients with complications of the procedure had no increase in the SF-36 subscales. However, in patients in whom the procedural complications appeared reversible, the lack of QoL increase was temporary, because these patients had a similar QoL as patients without complications at 12 months. Thus, the higher number of reversible complications after surgical ablation compared with catheter ablation, as reported by Boersma and colleagues, ${ }^{9}$ does not seem to affect QoL during follow-up in patients with advanced AF included in the AFACT study. ${ }^{10}$ Conversely, in patients with irreversible complications, pacemaker implantation in particular, QoL remained at the same decreased level compared with before the procedure.

The AFACT study reported more irreversible adverse effects in patients with GP ablation. ${ }^{10}$ Omitting GP ablation may decrease the number of irreversible complications and consequently increase QoL after thoracoscopic surgery for AF.

\section{Quality of Life After Atrial Fibrillation Ablation}

Improvement of AF-related symptoms is the primary objective of invasive treatment strategies for AF. However, improvement of QoL (beyond AF-related symptoms) is the most important objective of the patient undergoing the treatment. Subsequently, the results of QoL questionnaires may influence the cost-effectiveness of AF ablation and therefore affect the choice of therapy in patients with AF refractory to AAD. Previous studies on QoL after catheter ablation demonstrated significant improvement after ablation, particularly in patients without AF recurrence. ${ }^{16-18}$ Studies that compared catheter ablation with AAD therapy reported that QoL scores were significantly higher in patients who underwent catheter ablation than in patients with AAD treatment. ${ }^{19-21}$ Small,
Irreversible Adverse Event

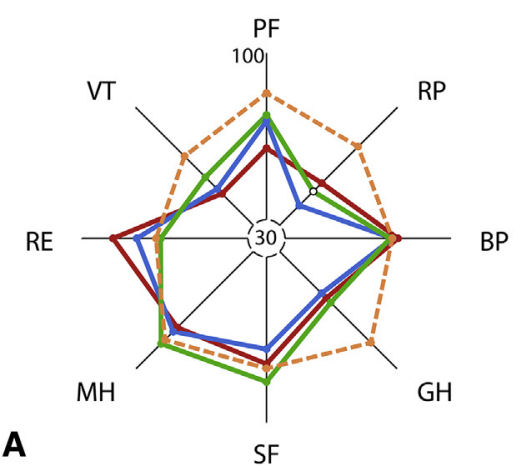

Reversible Adverse Event

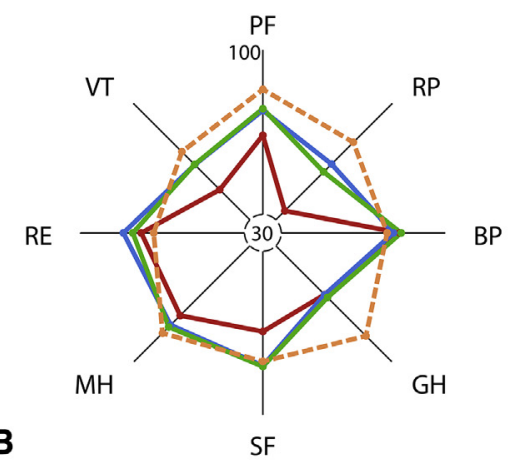

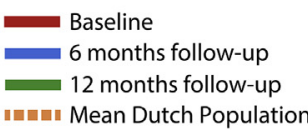

FIGURE 2. Radar chart with the SF-36 scores. The octagonal axes for each SF-36 subscale read excentric from central (30) to peripheral (100). The different conditions within 1 subscale can be read from the individual axes, whereas the surface of the entire graph indicates the aggregate QoL. QoL at baseline (red), 6 months follow-up (blue), and 12 months follow-up (green) are shown for (A) patients with an irreversible procedural complications and (B) patients with a reversible complication during the procedure or 12 months follow-up. Dutch population means are denoted by the dashed orange lines. $R E$, Role emotional; $V T$, vitality; $P F$, physical functioning; $R P$, role physical; $B P$, bodily pain; $G H$, general health; $S F$, social functioning; $M H$, mental health. 


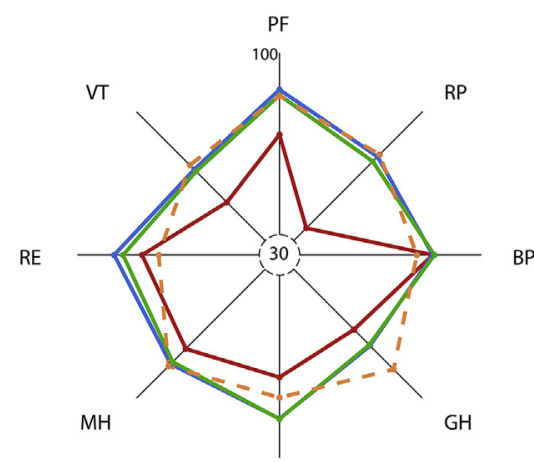

A

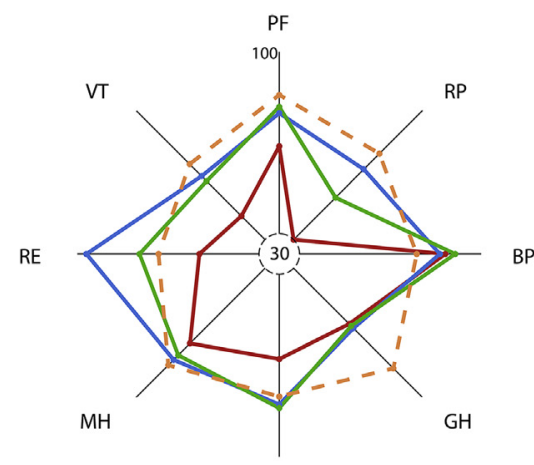

SF

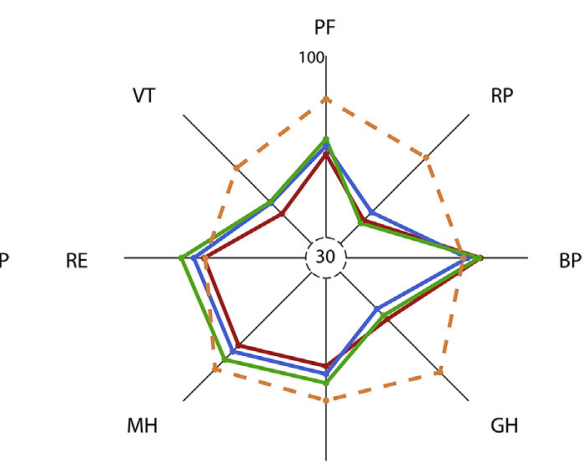

C

SF

FIGURE 3. A radar chart with the SF-36 scores at baseline (red), 6 months follow-up (blue), and 12 months follow-up (green) is shown for (A) patients without AF recurrence, (B) patient with $1 \mathrm{AF}$ recurrence, $(\mathrm{C})$ and patient with more than $1 \mathrm{AF}$ recurrence. Dutch population means are denoted by the dashed orange lines. $R E$, Role emotional; $V T$, vitality; $P F$, physical functioning; $R P$, role physical; $B P$, bodily pain; $G H$, general health; $S F$, social functioning; $M H$, mental health.

nonrandomized studies have reported an improvement of QoL after thoracoscopic surgery for AF, similar to the change in QoL that was observed after catheter ablation. $^{22,23}$ These observations are in line with the current study in patients with advanced AF undergoing a thoracoscopic procedure, which is more invasive than a catheter procedure. The absolute change in the different SF-36 scales in our study was larger than in the QoL substudy of the SAFE-T study, investigating restoration of sinus rhythm with AADs, but a minimal clinically important difference in SF-36 scales has not been defined for $\mathrm{AF}^{24}$ Our results imply that the recurrence of
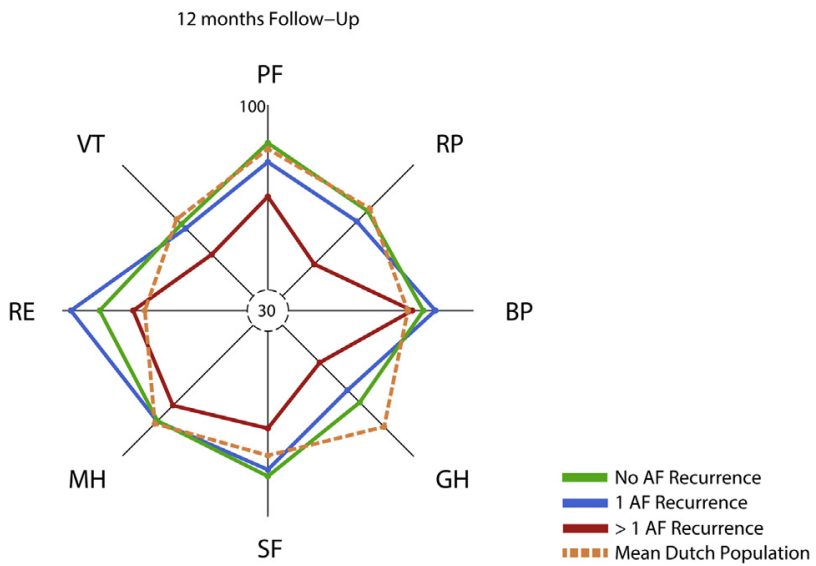

FIGURE 4. Improvement of QoL in relation to recurrences of AF. A radar chart with the SF-36 scores of patients with more than 1 AF recurrence (red), $1 \mathrm{AF}$ recurrence (blue), and no $\mathrm{AF}$ recurrences (green) is shown at 12 months follow-up after thoracoscopic AF surgery. Dutch population means are denoted by the dashed orange lines. $R E$, Role emotional; $V T$, vitality; $P F$, physical functioning; $R P$, role physical; $B P$, bodily pain; $G H$, general health; $S F$, social functioning; $M H$, mental health; $A F$, atrial fibrillation. arrhythmia and not the perceived invasiveness of the procedure drives the change in QoL.

In this prespecified subanalysis of the AFACT study, we demonstrate that in the overall population of patients undergoing thoracoscopic surgical ablation for $\mathrm{AF}$, there is a significant increase in SF-36-assessed QoL at 6 months after ablation, which remains 12 months after the procedure. A relatively constant and remaining increase in QoL after various cardiac surgery procedures has been described. ${ }^{25}$ We further show that the rhythm outcome of the procedure influences the gain in QoL. Patients without recurrence improved significantly more than patients with AF recurrences. The latter showed an increase in mental health status after the procedure, but not in physical health. AF recurrence was defined as at least 1 episode of symptomatic or asymptomatic AF recorded on ECG or 24-hour Holter lasting more than 30 seconds. Because this is an all-or-no definition, it does not take into account how symptoms relate to the burden of AF. We show that patients in whom a single AF recurrence is documented during 1 year of follow-up improve in QoL similar to patients without AF recurrences. However, multiple AF recurrences are associated with absence of $\mathrm{QoL}$ improvement. We found no QoL difference with regard to gender. $^{26}$

Previous studies investigated the impact of the AF burden or symptom burden on QoL after catheter ablation. Similar to the results after thoracoscopic surgery presented in this article, patients with a high burden of AF show no improvement or even a decrease of QoL after catheter ablation. Furthermore, patients with demonstrated AF recurrences, but with a low AF burden, showed significant QoL improvement after ablation. ${ }^{27}$ Also, it has been shown that patients with symptomatic AF before ablation may experience asymptomatic episodes after the procedure. ${ }^{28}$ 
TABLE 5. Univariable and multivariable predictors of change in Physical Component Summary and Mental Component Summary scores at 12 months after thoracoscopic surgical ablation

\begin{tabular}{|c|c|c|c|c|c|c|c|c|}
\hline & \multicolumn{4}{|c|}{ Change in PCS after 12 mo } & \multicolumn{4}{|c|}{ Change in MCS after $12 \mathrm{mo}$} \\
\hline & \multicolumn{2}{|c|}{ Univariable } & \multicolumn{2}{|c|}{ Multivariable } & \multicolumn{2}{|c|}{ Univariable } & \multicolumn{2}{|c|}{ Multivariable } \\
\hline & $\mathbf{B}$ & $P$ & $\mathbf{B}$ & $P$ & $\mathbf{B}$ & $P$ & $\mathbf{B}$ & $P$ \\
\hline Age (y) & -0.097 & .245 & & & 0.003 & .979 & & \\
\hline Gender (female) & 0.103 & .945 & & & -0.027 & .988 & & \\
\hline Type AF (persistent) & -0.384 & .775 & & & -0.866 & .581 & & \\
\hline AF duration (y) & -0.098 & .448 & & & -0.030 & .840 & & \\
\hline History of PVI (yes) & -2.436 & .114 & & & -0.089 & .961 & & \\
\hline $\mathrm{CHA}_{2} \mathrm{DS}_{2} \mathrm{VASc}$ & -0.424 & .422 & & & 0.833 & .175 & & \\
\hline BMI & -0.196 & .267 & & & 0.287 & .163 & & \\
\hline $\mathrm{AF}$ recurrences at $6 \mathrm{mo}$ (yes) & -5.049 & .004 & -1.312 & .550 & -3.429 & .095 & -1.288 & .424 \\
\hline $\mathrm{AF}$ recurrences at $12 \mathrm{mo}$ (yes) & -6.037 & $<.001$ & -5.373 & .001 & -1.318 & .434 & & \\
\hline $\mathrm{AAD}$ at 6 mo (yes) & -5.841 & .002 & -3.408 & .068 & -1.834 & .404 & & \\
\hline $\mathrm{AAD}$ at $12 \mathrm{mo}$ (yes) & -0.004 & .681 & & & -0.005 & .659 & & \\
\hline Major adverse events (yes) & -1.574 & .384 & & & -4.147 & .049 & -3.23 & .049 \\
\hline GP ablation (yes) & 1.175 & .376 & & & -0.201 & .897 & & \\
\hline QoL at baseline & -0.485 & $<.001$ & -0.536 & $<.001$ & -0.651 & $<.001$ & -0.616 & $<.001$ \\
\hline
\end{tabular}

$P C S$, Physical Component Summary; $M C S$, Mental Component Summary; $A F$, atrial fibrillation; $P V I$, pulmonary vein isolation; $\mathrm{CHA}_{2} D \mathrm{~S}_{2} V A S c$, congestive heart failure [C], hypertension $[\mathrm{H}]$, age $>75$ years (2 points) $\left[\mathrm{A}_{2}\right]$, diabetes [D], previous stroke (2 points) [ $\left.\mathrm{S}_{2}\right]$, vascular disease [V], age $65-74$ years [A], female sex [Sc]; $B M I$, body mass index; $A A D$, antiarrhythmic drug; $G P$, ganglion plexus; $Q o L$, quality of life.

Evidently, asymptomatic AF recurrences are unlikely to affect QoL.

\section{Study Limitations}

AFACT was designed to evaluate the efficacy of GP ablation on AF outcome in patients undergoing thoracoscopic surgery for AF. Although the study was not designed or powered for specific changes in QoL, changes in the overall QoL as measured by the SF-36 questionnaire

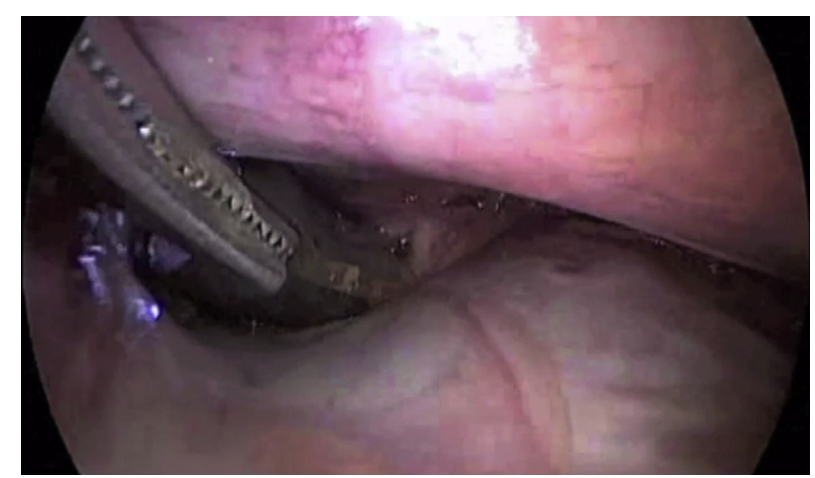

VIDEO 1. Dr Antoine Driessen gives a short summary of the main messages of the current study on QoL in the AFACT population and provides an explanation on a video of the thoracoscopic procedure. Video available at: http://www.jtcvsonline.org/article/S0022-5223(17) 32134-7/fulltext. were a prespecified end point. The main driver of QoL outcome in this analysis was AF recurrences, although 1 of the multivariable predictors of lack of QoL increase was a preexisting low PCS or MCS. It cannot be excluded that patients were more likely to report improved QoL, because all underwent a procedure. However, the difference in reported outcome between patients with and without AF recurrences or irreversible complications argues against that. It should be noted that although we followed up patients more rigorously than the guidelines require, periodic Holter monitoring may underestimate the true incidence of AF recurrences. However, because asymptomatic AF recurrences are not expected to affect general QoL, this likely did not affect our conclusions.

The current analysis was restricted to 1 year of follow-up. Is cannot be excluded that during a longer follow-up period different results are achieved, in particular with respect to patients with (irreversible) procedural complications.

\section{CONCLUSIONS}

Patients with symptomatic advanced AF undergoing thoracoscopic surgery for AF had a substantial improvement in QoL, regardless of additional GP ablation. AF recurrences were the most important determinant for lack of QoL improvement. QoL in patients without or with a single AF recurrence increased to values similar to those for the Dutch reference population. Patients with multiple AF recurrences had no increase in $\mathrm{QoL}$ and remained at 
the low baseline level. Irreversible, but not reversible, complications of the procedure were associated with lack of QoL improvement.

\section{Conflict of Interest Statement}

Drs Driessen and de Groot report a financial relationship with Atricure. Dr de Groot is a consultant for Daiichi Sankyo and received research funding from St Jude Medical and AtriCure, and personal grants from the Dutch Heart Foundation and the Netherlands Organization for Scientific Research. All other authors have nothing to disclose with regard to commercial support.

\section{References}

1. Chugh SS, Havmoeller R, Narayanan K, Singh D, Rienstra M, Benjamin EJ, et al. Worldwide epidemiology of atrial fibrillation: a Global Burden of Disease 2010 Study. Circulation. 2014;129:837-47.

2. Naccarelli GV, Varker H, Lin J, Schulman KL. Increasing prevalence of atrial fibrillation and flutter in the United States. Am J Cardiol. 2009;104:1534-9.

3. Hagens VE, Ranchor AV, Van Sonderen E, Bosker HA, Kamp O, Tijssen JG, et al. Effect of rate or rhythm control on quality of life in persistent atrial fibrillation. Results from the Rate Control Versus Electrical Cardioversion (RACE) Study. J Am Coll Cardiol. 2004;43:241-7.

4. Kirchhof P, Breithardt G, Bax J, Benninger G, Blomstrom-Lundqvist C, Boriani $\mathrm{G}$, et al. A roadmap to improve the quality of atrial fibrillation management: proceedings from the fifth Atrial Fibrillation Network/European Heart Rhythm Association consensus conference. Europace. 2016;18:37-50.

5. Wokhlu A, Monahan KH, Hodge DO, Asirvatham SJ, Friedman PA, Munger TM, et al. Long-term quality of life after ablation of atrial fibrillation the impact of recurrence, symptom relief, and placebo effect. J Am Coll Cardiol. 2010;55: 2308-16.

6. Fichtner S, Deisenhofer I, Kindsmuller S, Dzijan-Horn M, Tzeis S, Reents T, et al. Prospective assessment of short- and long-term quality of life after ablation for atrial fibrillation. J Cardiovasc Electrophysiol. 2012;23:121-7.

7. Erdogan A, Carlsson J, Neumann T, Berkowitsch A, Neuzner J, Hamm CW, et al Quality-of-life in patients with paroxysmal atrial fibrillation after catheter ablation: results of long-term follow-up. Pacing Clin Electrophysiol. 2003;26: 678-84.

8. Calkins H, Kuck KH, Cappato R, Brugada J, Camm AJ, Chen SA, et al. 2012 HRS/EHRA/ECAS Expert Consensus Statement on Catheter and Surgical Ablation of Atrial Fibrillation: recommendations for patient selection, procedural techniques, patient management and follow-up, definitions, endpoints, and research trial design. Europace. 2012;14:528-606.

9. Boersma LV, Castella M, van Boven W, Berruezo A, Yilmaz A, Nadal M, et al. Atrial fibrillation catheter ablation versus surgical ablation treatment (FAST): a 2-center randomized clinical trial. Circulation. 2012;125:23-30.

10. Driessen AH, Berger WR, Krul SP, van den Berg NW, Neefs J, Piersma FR, et al Ganglion plexus ablation in advanced atrial fibrillation: the AFACT Study. J Am Coll Cardiol. 2016;68:1155-65.

11. de Groot JR, Driessen AH, Van Boven WJ, Krul SP, Linnenbank AC, Jackman WM, et al. Epicardial confirmation of conduction block during thoracoscopic surgery for atrial fibrillation-a hybrid surgicalelectrophysiological approach. Minim Invasive Ther Allied Technol. 2012;21: 293-301.

12. Edgerton JR, Jackman WM, Mack MJ. A new epicardial lesion set for minimal access left atrial maze: the Dallas lesion set. Ann Thorac Surg. 2009; 88:1655-7.

13. Ware JE, Kosinski M, Keller SD. SF-36 Physical and Mental Health Summary Scales: A User's Manual. Boston, MA: The Health Institute, New England Medical Center; 1994.
14. Aaronson NK, Muller M, Cohen PD, Essink-Bot ML, Fekkes M, Sanderman R, et al. Translation, validation, and norming of the Dutch language version of the SF-36 Health Survey in community and chronic disease populations. J Clin Epidemiol. 1998;51:1055-68.

15. Kirchhof P, Benussi S, Kotecha D, Ahlsson A, Atar D, Casadei B, et al. 2016 ESC Guidelines for the management of atrial fibrillation developed in collaboration with EACTS: The Task Force for the management of atrial fibrillation of the European Society of Cardiology (ESC)Developed with the special contribution of the European Heart Rhythm Association (EHRA) of the ESC. Endorsed by the European Stroke Organisation (ESO). Eur Heart J. 2016;37:2893-962.

16. Reynolds MR, Walczak J, White SA, Cohen DJ, Wilber DJ. Improvements in symptoms and quality of life in patients with paroxysmal atrial fibrillation treated with radiofrequency catheter ablation versus antiarrhythmic drugs. Circ Cardiovasc Qual Outcomes. 2010;3:615-23.

17. Walfridsson H, Walfridsson U, Nielsen JC, Johannessen A, Raatikainen P, Janzon M, et al. Radiofrequency ablation as initial therapy in paroxysmal atrial fibrillation: results on health-related quality of life and symptom burden. The MANTRA-PAF trial. Europace. 2015;17:215-21.

18. Berger WR, Krul SP, van der Pol JA, van Dessel PF, Conrath CE, Wilde AA, et al. Documented atrial fibrillation recurrences after pulmonary vein isolation are associated with diminished quality of life. J Cardiovasc Med (Hagerstown). 2016;17:201-8

19. Wilber DJ, Pappone C, Neuzil P, De Paola A, Marchlinski F, Natale A, et al. Comparison of antiarrhythmic drug therapy and radiofrequency catheter ablation in patients with paroxysmal atrial fibrillation: a randomized controlled trial. JAMA. 2010;303:333-40.

20. Jais P, Cauchemez B, Macle L, Daoud E, Khairy P, Subbiah R, et al. Catheter ablation versus antiarrhythmic drugs for atrial fibrillation: the A4 study. Circulation. 2008:118:2498-505.

21. Wazni OM, Marrouche NF, Martin DO, Verma A, Bhargava M, Saliba W, et al. Radiofrequency ablation vs antiarrhythmic drugs as first-line treatment of symptomatic atrial fibrillation: a randomized trial. JAMA. 2005;293: 2634-40.

22. Pruitt JC, Lazzara RR, Dworkin GH, Badhwar V, Kuma C, Ebra G. Totally endoscopic ablation of lone atrial fibrillation: initial clinical experience. Ann Thorac Surg. 2006;81:1325-31.

23. Kasirajan V, Spradlin EA, Mormando TE, Medina AE, Ovadia P, Schwartzman DS, et al. Minimally invasive surgery using bipolar radiofrequency energy is effective treatment for refractory atrial fibrillation. Ann Thorac Surg. 2012;93:1456-61.

24. Singh SN, Tang XC, Singh BN, Dorian P, Reda DJ, Harris CL, et al. Quality of life and exercise performance in patients in sinus rhythm versus persistent atrial fibrillation: a Veterans Affairs Cooperative Studies Program Substudy. J Am Coll Cardiol. 2006;48:721-30.

25. Grady KL, Lee R, Subacius H, Malaisrie SC, McGee EC Jr, Kruse J, et al. Improvements in health-related quality of life before and after isolated cardiac operations. Ann Thorac Surg. 2011;91:777-83.

26. Shah SV, Kruse J, Andrei AC, Li Z, Malaisrie SC, Knight BP, et al. Gender differences in outcomes after surgical ablation of atrial fibrillation. $J$ Thorac Cardiovasc Surg. 2016;151:391-8.e2.

27. Mantovan R, Macle L, De Martino G, Chen J, Morillo CA, Novak P, et al. Relationship of quality of life with procedural success of atrial fibrillation (AF) ablation and postablation AF burden: substudy of the STAR AF randomized trial. Can J Cardiol. 2013;29:1211-7.

28. Verma A, Champagne J, Sapp J, Essebag V, Novak P, Skanes A, et al. Discerning the incidence of symptomatic and asymptomatic episodes of atrial fibrillation before and after catheter ablation (DISCERN AF): a prospective, multicenter study. JAMA Intern Med. 2013;173:149-56.

Key Words: health-related quality of life, atrial fibrillation, thoracoscopic surgery, ganglion plexus ablation 